
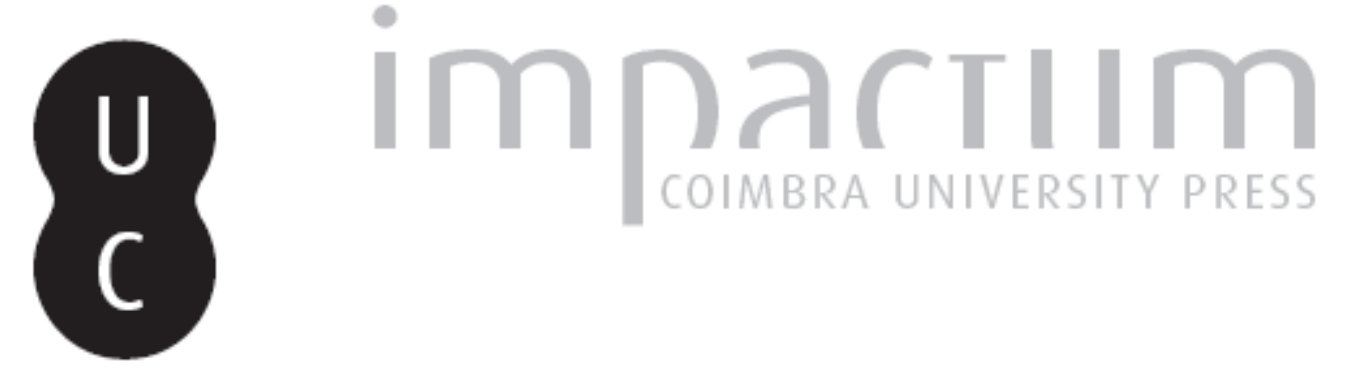

Reclusão e proteção: os judeus em Portugal na crise do século XIV

Autor(es): $\quad$ Nogueira, Carlos Roberto Figueiredo

Publicado por: Centro de História da Sociedade e da Cultura

URL persistente:

URI:http://hdl.handle.net/10316.2/39427

DOI:

DOI:http://dx.doi.org/10.14195/1645-2259_12_6

Accessed : $\quad$ 26-Apr-2023 04:47:43

A navegação consulta e descarregamento dos títulos inseridos nas Bibliotecas Digitais UC Digitalis, UC Pombalina e UC Impactum, pressupõem a aceitação plena e sem reservas dos Termos e Condições de Uso destas Bibliotecas Digitais, disponíveis em https://digitalis.uc.pt/pt-pt/termos.

Conforme exposto nos referidos Termos e Condições de Uso, o descarregamento de títulos de acesso restrito requer uma licença válida de autorização devendo o utilizador aceder ao(s) documento(s) a partir de um endereço de IP da instituição detentora da supramencionada licença.

Ao utilizador é apenas permitido o descarregamento para uso pessoal, pelo que o emprego do(s) título(s) descarregado(s) para outro fim, designadamente comercial, carece de autorização do respetivo autor ou editor da obra.

Na medida em que todas as obras da UC Digitalis se encontram protegidas pelo Código do Direito de Autor e Direitos Conexos e demais legislação aplicável, toda a cópia, parcial ou total, deste documento, nos casos em que é legalmente admitida, deverá conter ou fazer-se acompanhar por este aviso.

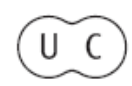


evista de História da Sociedade e da Cultura

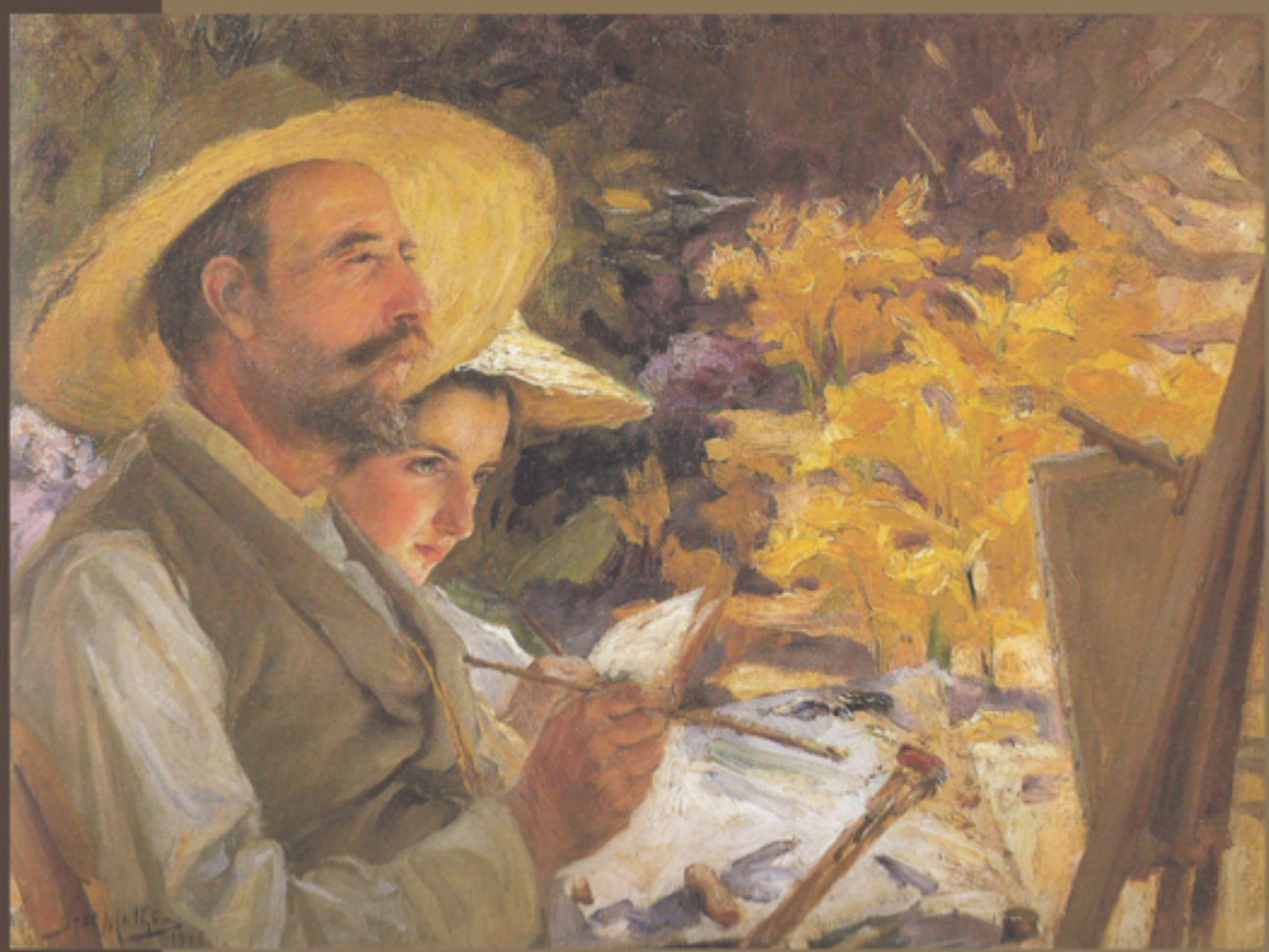

Centro de História da Sociedade e da Cultura Universidade de Coimbra 


\title{
Reclusão e proteção: os judeus em Portugal na Crise do século XIV*
}

\author{
Carlos Roberto Figueiredo Nogueira \\ Faculdade de Filosofia, Letras e Ciências Humanas \\ Universidade de São Paulo, Brasil \\ crfnogue@usp.br
}

Texto recebido em /Text submitted on: 28/10/2011

Texto aprovado em /Text approved on: 16/05/2012

Resumo/Abstract:

Ao pretender-se estudar os judeus portugueses na crise do século XIV, revisitamos a legislação que lhes concernia e, de igual, as práticas que as fontes revelam.

A par com uma evolução negativa acerca dos judeus, transcorre-se para uma oposição entre a ideia do perigo para a sociedade e a necessidade da sua colaboração nos aspectos vedados aos cristãos, fonte de medidas políticas coercitivas e de práticas protetoras à comunidade hebraica.

Wanting to study the portuguese jews in the crisis of the fourteenth century, we revisit the law and the pratices to them.

Along with a negative trend about Jews unfolds to an opposition between the idea of danger to society and the need for collaboration in aspects not accessible to Christians, source of coercive measures policies and practices of the Jewish community protective.

Palavras chave/Keywords:

Judeus em Portugal; Cortes portuguesas; Crise século XIV.

Jews in Portugal; Portuguese cortes; Crisis $14{ }^{\text {th }}$ century.

* Professor titular da Faculdade de Filosofia Letras e Ciências Humanas, Departamento de História, Universidade de São Paulo, Brasil; Conselheiro da Cátedra Jaime Cortesão e Coordenador do GEMPO (Grupo de Estudos Medievais Portugueses); membro da Academia Portuguesa da História. 
É bem conhecida a situação dos judeus como depositários das expressões do medo e do ódio da sociedade medieval, em especial no imaginário tumultuado em tempos da crise do século XIV. O judeu é, por excelência, o conspirador, o responsável pelas calamidades, pelo retardamento da segunda Parusia e pelo engrandecimento da cólera divina.

Apesar de, em Portugal e mesmo na quase totalidade da Península Ibérica, os judeus terem prosperado e criado afinidades e relações sociais aparentemente seguras, a crise do século XIV trará para o âmbito ibérico a busca da "quinta-coluna satânica", empenhada em fustigar e ameaçar o rebanho cristão.

O espírito de tolerância modificou-se gradualmente, a crise exacerbou "paixões e desconfianças que vinham de muito longe e a tornar os 'infiéis' em bodes expiatórios das desgraças que vinha sofrendo o povo de Cristo. $\mathrm{O}$ aumento do número de judeus constituía factor relevante nessa modificação"'.

Só raramente se registraram ataques a judeus ou judiarias no século XIV e sem a característica de extrema violência dos pogroms registrados em outras partes da Europa. Segundo Maria José Pimenta Ferro Tavares, apenas o ataque em Lisboa datado de 1449, ou seja, do século XV, poderia ser classificado como pogrom ${ }^{2}$.

É assim que no meio da agitação causada pelo assassinato do Andeiro, nas gentes de Lisboa "geerou sse amtrelles hûua huniom de mortall hodio, contra quaaesquer que sua emteemçom nom tinham, em tanto que nenhuum logar era seguro, aaquelles que nom seguiam a sua opiniom"s, resolvendo,

1 MARQUES, A. H de Oliveira, Portugal na Crise dos séculos XIV e XV. Nova História de Portugal, IV, dirig. por MARQUES, A. H. de Oliveira e SERRÃO, Joel, Lisboa: Editorial Presença, 1987, p. 397. Ver ainda MORENO, Humberto Baquero, Exclusão social e minorias étnicas. e Maria Alegria Fernandes Marques, As minorias na legislação sinodal portuguesa medieval. in Minorias étnicas e religiosas em Portugal. História e actualidade. Curso de Inverno 2002. Coimbra: Instituto de História Económica e Social - Faculdade de Letras da Universidade de Coimbra, 2002, p. 19-32 e 33-47, respectivamente.

2 TAVARES, Maria José Pimenta Ferro, Os judeus em Portugal no século XIV. Lisboa: Universidade Nova de Lisboa, 1982, p. 228.

3 Chronica DelRey D. Joam I de Boa Memoria e dos Reys de Portugal o Decimo: primeira parte [-terceira... . ...: offerecida a Magestade DelRey Dom Joam o IV. N. Senhor de miraculosa memoria / composta por Fernam Lopez. Em Lisboa: a custa de Antonio Alvarez Impressor DelRey, 1644, capítulo XV, I, p. 31, grifos nossos. 
então, roubar aos judeus, o que parecia lídimo uma vez que eles eram os "culpados" da crise vivida.

Em Portugal, a imposição do sinal amarelo aos judeus foi muito tardia. Decretada pelo IV Concílio de Latrão em 1215, ela só será imposta (diga-se de passagem, sem nenhuma convicção) no reinado de D. Afonso $\mathrm{IV}^{4}$.

E singularmente é D. Dinis, em cujo reinado se anuncia a crise, que promulgará uma série de leis que dizem respeito ao trato com os judeus: leis que determinam o modo de pagar dívidas a judeus ${ }^{5}$ (1314), ou que definem a invalidade das dívidas com os judeus após $20 \operatorname{anos}^{6}$ (1321), ou uma outra lei, de $1310^{7}$, que proíbe, também aos judeus, "contrauto de conlluyo ou d'engano com cristaão" e que será singularmente retomada (reforçada?) em $1315^{8}$.

E insiste na preocupação de vigiar o endividamento seja na "Ley que todos os contrautos que forem feitos antre cristaãos e Judeus que se façam perante os Juizes. Ou doutra guisa nom ualham”, de $1314^{9}$, seja na lei de 1315 "Como os Juizes E tabaliaães deuem ser Regjidentes em seus ofiçios para se fazerem perante elles os contraitos dos Judeus" 10.

Com estas determinações, o rei buscava estabelecer posturas de ordem econômica destinadas a proteger aos devedores e regular os contratos. Era preciso demarcar o lugar e, em se tratando de judeus, a "falta de lugar" na economia e na sociedade desequilibradas pelas más-colheitas e pela fome.

O sucessor de D. Dinis, seu filho, D. Afonso IV, insiste na legislação que envolve fundamentalmente os contratos e as dívidas, como as promulgadas em 1349 ". Uma das leis então publicadas "suspende" as execuções dos bens por dívidas pelos judeus e a outra, retomando uma lei de 1325, a reafirma e esclarece, proibindo a usura e impedindo as formas de empréstimo em espécie (seria uma preocupação com o desabastecimento?), pois "muytos

4 TAVARES, Maria José Pimenta Ferro, op. cit., p. 398.

5 Livro das leis e posturas. Lisboa: Universidade de Lisboa, 1971, p. 90.

${ }^{6}$ Ibidem, p. 87.

7 Ordenações del-Rei Dom Duarte. Lisboa: Fundação Calouste Gulbenkian, 1988, p. 282.

8 Ibidem, p. 300.

9 Ibidem, p. 295-296.

${ }^{10}$ Ibidem, p. 298-299.

${ }^{11}$ Livro das leis e posturas, op. cit., p. 443-448. 
fidalgos e homens boons (...) e lauradores e meesteiraees que eram Ricos e ffectos e auyam per que nos poderiam fazer seruiço quando nos compria e fazia mester com caualos e armas (...) caeram em pobreza fazendo taaes contrautos em que Recebiam muy grades danos. Recebendo pequena quantia de dinheiros ou outras cousas que logo dauan por dinheiros por muy meores quantias que aquelas em que as Recebiam. E emquanto durauam esses dinheiros fossen despesos em cousas que a eles nom conpridoiras e em tanto leixauam desperecer sas quintãas e logares e herdades e outros beens que no laurauam nem husauam de seus mesteres. E por estas diuydas, lhos uendian depois a maa barata os beens que auyam a meus preço Por a qual Razon cayan em mingua e pobreza"'12. Lei que se preocupa com a ameaça de pauperização dos seus súditos, mas fundamentalmente, como frisamos acima, pretende evitar o enfraquecimento do serviço militar prestado ao Rei.

Uma outra norma datada de Lisboa em 1327 coloca os judeus que cometem crimes contra cristãos sob a jurisdição do alcaide, revertendo o costume comum aos judeus de demandarem "perante seu arraby"13. No entanto, se o costume é revogado, o privilégio concedido por D. Dinis aos judeus e mouros, que em certos casos seu testemunho valha mais que de cristão ${ }^{14}$, vai em sentido inverso, sendo mantido o privilégio no artigo $4 .^{\circ}$ dos Capítulos Particulares das Cortes de 1331.

No entanto, a presença dos judeus é uma necessidade; aos judeus cabe o "trato ilícito" do manuseio do "vil metal", vedado aos cristãos. O judeu usurário, o prestamista insubstituível, era odioso, mas necessário e útil ${ }^{15}$. Mesmo o Concílio Lateranense de 1215, que impõe medidas restritivas aos judeus, não proíbe a usura, apenas as usuras "pesadas e excessivas"16, abrindo caminho para a aceitação dos juros moderados.

${ }^{12}$ Livro das leis e posturas, op. cit., p. 444. Destaque nosso, aqui e ao longo do texto.

${ }^{13}$ Documentos do Arquivo Histórico da Câmara Municipal de Lisboa. Livro de Reis. I. Lisboa: Câmara Municipal de Lisboa, 1987, p. 104.

${ }^{14}$ Ibidem, p. 149.

${ }^{15}$ LE GOFF, Jacques, A Civilização do Ocidente Medieval. II. Lisboa: Editorial Estampa, p. 78. Ver ainda IBAÑEZ, J., La doctrine de l'Église et les réalités économiques au XIII ${ }^{e}$ siècle. Paris: PUF, 1967.

${ }^{16}$ KRIEGEL, Maurice, "JUDEUS" in J. Le Goff \& J-C Schmitt (coords.), Dictionnaire Raisonné de L'Occident Médiéval, Paris: Fayard, 1999, p. 41. 
Afonso IV deixa transparecer essa necessidade num arrazoado singular dos Capítulos Gerais das Cortes de Lisboa de 1352, no qual lhe é reclamado que os judeus arrendam terras com prejuízo dos cristãos, ao qual o rei responde que de tal arrendamento vêm lucros para a coroa, prometendo estudar a forma de atender a queixa.

É nessa dialética de medidas coercitivas e medidas que protegem as comunidades judaicas, que acreditamos poder situar as determinações do reinado de D. Pedro I.

D. Pedro era um monarca nascido cristão, o que tornava impossível não partilhar do imaginário comum a todo o Ocidente e que envolvia a sociedade, ao mesmo tempo em que, no plano político, a realidade do alcance do poder real apontava para uma relativização de suas ações contra a Igreja.

Normatização, tentativa de regularização, ações que parecem ser a chave da política de D. Pedro I em relação a judeus e mouros.

Nas Cortes de Elvas de 1361, o monarca estabelece, no artigo 40. , a separação da comunidade cristã das minorias infiéis, completada com a proibição de os mesmos circularem fora do bairro após o fechamento de suas portas.

É claro que, apesar da existência de uma legislação canônica, à qual se adicionará a partir da segunda metade do século XIV a legislação régia, a prática estava longe de ser eficaz. Conforme nos diz Margarida Ventura, "nas constituições sinodais do reino abundam admoestações contra os fiéis que alugam casas a judeus ou com eles convivem mais do que o estritamente necessário por contactos profissionais"17.

Do ponto de vista do exercício da religiosidade no cotidiano, aos judeus e mouros é imposta, por D. Pedro I, a separação física legal. Estabelecida no século XIII pelo IV Concílio de Latrão, esta separação só tornou-se oficial em Portugal nas Cortes de 1361, apesar de que se pode questionar a eficácia da medida, uma vez que os judeus permaneceram residindo fora das judiarias, alguns com cartas régias que os isentavam de tal obrigação, o que provoca

${ }^{17}$ Contributo para uma Leitura Social do espaço da Lisboa quatrocentista: o debate sobre a localização das judiarias. Revista Portuguesa da História, Coimbra, XXXVI, 2002/2003, p. 234. 
sucessivos protestos ao fundador da dinastia de Avis, nomeadamente nas Cortes de Coimbra de 1390 e nas de Leiria-Santarém de $1433^{18}$.

Reza o artigo 40. ${ }^{\circ}$ das Cortes de Elvas: “... em alghûus logares do nosso Senhorio moram Judeus e mouros mesturados antre os christaãos e fazem alghûuas cousas desordinhadas de que os christaãos reçebem scandalo e nojo. E que fosse nossa merçee que mandassemos que morassem em logar apartado e nom antre os christaãos", ao que responde o monarca: “... que se faça como per elles he pedido. E esto se entenda nas villas grandes e nos outros logares hu ouver ata dez judeus ou Mouros e mandamos aas Justiças que lhis dem logares aguisados pera sa morada ..."

Sabemos que a reclusão dos judeus em um espaço específico foi uma iniciativa deste monarca, mas podemos entender a medida como meramente uma ação antijudaica, primeiro episódio de uma triste repressão que se acirrará por séculos? E por que a medida só foi aplicada mais de um século após ter sido decretada em Latrão em 1215?

Ou devemos pensar que a delimitação do espaço urbano tenta normalizar, evitar os inevitáveis conflitos, acirrados pela crise do século XIV, quando de um lado aumentam as cidades e, de outro, reduzem-se espaços, aumento que contudo, não as tornam mais dinâmicas, mas sim mais miseráveis e conflituosas, com o recebimento da população dos campos, lavradores empobrecidos em busca de soluções para a sua sobrevivência.

A riqueza da cidade atrai e fascina, mas é uma riqueza fundamentalmente concentrada que tornará os novos migrantes apenas em "ventres ao sol"20.

É nesse espaço alargado que as tensões se intensificam. A relativa tolerância que conviveu por séculos com uma alimentação "erudita", por parte do clero, da maldade intrínseca dos "assassinos de Cristo" é minada pela crise que exacerba as desconfianças e transforma os infiéis, em especial os judeus, em uma "quinta-coluna" responsável pelas desgraças do povo

18 VENTURA, Margarida, Igreja e poder no século XV: dinastia de Avis e liberdades eclesiásticas (1383-1450). Lisboa: Colibri, 1997, p. 476-477.

${ }^{19}$ Cortes portuguesas. Reinado de D. Pedro I (1357-1367). Edição preparada por MARQUES, A. H. de Oliveira e DIAS, Nuno José Pizarro Pinto. Lisboa: Centro de Estudos Históricos, Faculdade de Ciências Sociais e Humanas, Universidade Nova de Lisboa Instituto Nacional de Investigação Científica, 1986, p. 52.

${ }^{20}$ MOLLAT, Michel et WOLFF, Philippe, Ongle bleues, Jacques et Ciompi: les révolutions populaires en Europe au XIV et XVte siécles. Paris: s. n., 1970. 
cristão. Os espaços urbanos se ideologizam e apontam as responsabilidades: não apenas a folclórica "riqueza judaica", mas também a estabilidade desta comunidade necessariamente urbana e solidária despertam a cobiça dos que pretendem acrescentamentos ou daqueles que nada possuem.

O espaço na cristandade tem de ser delimitado. Espaço sagrado, mas também espaço público, o que provocaria inevitáveis conflitos. E aí deixamos de lado o conflito entre religiões, para entrar na religiosidade cotidiana.

Assim, cinco anos após as cortes, em setembro de 1366, fecham-se os bairros "infiéis" e proíbe-se a frequência aos cristãos após o pôr-do-sol, sobretudo, às mulheres: "Sabede que a mim foy dicto per alguuns homens boons dignos de creer que em alguuns lugares do meu senhorio, molheres solteiras e viuvas e algûas outras casadas per aazo e engano e arteirice do diaboo que he enmigo antiigo de toda a christandade faziam pecado de fornizio com alguuns homens d'outra ley assy nos arraualdes hu maram (sic) os mouros como nas judarias hi (sic) moram os judeus" ${ }^{21}$. O texto prossegue, com a deliberação régia: "Tenho por bem e mando que nemhûa molher christaa de qualquer condiçom que seja nom entre no arraualde dessa cidade de noyte saluo que possam hir quando lhes mester fizer pollo caminho que uay da porta de Sancto Andre pera Sancta Barbora pella calçada"’22, abrindo uma exceção no que concerne à judiaria. Enquanto o monarca limitava-se a proibir a frequência da mouraria às mulheres cristãs, sob pena de morte, o mesmo não acontecia para a judiaria. Aqui, era-lhes permitida a entrada, acompanhadas por um cristão adulto, se fossem viúvas ou solteiras, e por dois, em se tratando de mulheres casadas. E, no caso de não possuírem acompanhantes, era aconselhado que solicitassem aos homens do rei que guardavam a judiaria que as acompanhassem. Não podendo evitar o comparecimento de mulheres cristãs à zona comercial judaica, pelo menos garantia a sua honra em especial, evitando a possível infâmia de um adultério com um infiel.

${ }^{21}$ Chancelarias Portuguesas. D. Pedro I (1357-1367). Edição preparada por MARQUES, A. H. de Oliveira. Lisboa: Instituto Nacional de Investigação Científica - Centro de Estudos Históricos, Faculdade de Ciências Sociais e Humanas, Universidade Nova de Lisboa, 1984, p. 535, n. $^{\circ} 1131$.

${ }^{22}$ Ibidem. 
A questão da sexualidade ilícita (e muito mais ilícita, uma vez que se trata de uma fornicação com infiéis) aqui é fundamental, e isto ainda fica mais patente no texto, que ordena que “... çarrem logo os dictos judeus a porta do poço da fotea e a porta do chancudo que uay sair a putaria "'23.

Ou seja, não se trata de manter as mulheres cristãs respeitáveis apartadas dos judeus e da mouraria, mas apartar inclusive às mulheres do século de uma contaminação com os adversários da fé cristã.

O tema não é novo, pois já o encontramos nas Cortes de Santarém realizadas por Afonso IV em 1331. Em seus Capítulos Gerais, no artigo 41. ${ }^{\circ}$, traz a resposta do rei sobre o descumprimento do foral, por parte dos mordomos, que admitem a prostituição, fora a de mulher cristã com mouro ou judeu e que se então forem achados juntos serão presos "e levam deles algo" 24 .

Mas caberia lembrar que no artigo $56 .^{\circ}$ das Cortes de Elvas, que trata de "que quando aconteçe que chegamos a alguum logar ou villa nos e nossos filhos Meestres Ricos homens e outros poderosos hu ha veuuas que viuem honestamente e outras mulheres que nom teem hy seus maridos, pousam com ellas e (...) que por esta razom guaanham maa nomeada", ordena o Rei D. Pedro: “... que (...) nom pousem(...) com as boas donas veuuas nem com as molheres homrradas casadas se hi nom forem seus Maridos" 25 .

Vale lembrar também que essa radical segregação tem vida um tanto breve, pois a determinação que inclusive cerrava os judeus na judiaria após o por do sol, sob pena de açoite, é abrandada dois meses depois, permitindo aos judeus circularem pela cidade, até que tangessem as Ave-Marias, na sé de Lisboa ${ }^{26}$.

${ }^{23}$ Ibidem, p. 536.

${ }^{24}$ Cortes portuguesas. Reinado de D. Afonso IV (1325-1357). Edição preparada por MARQUES, A. H. de Oliveira, RODRIGUES, Maria Teresa Campos e DIAS, Nuno José Pizarro Pinto. Lisboa: Centro de Estudos Históricos, Faculdade de Ciências Sociais e Humanas, Universidade Nova de Lisboa - Instituto Nacional de Investigação Científica, 1982, p. 74. Sobre a matéria, ver BEIRANTE, Maria Ângela V. da Rocha, As mancebias nas cidades medievais portuguesas, in A mulher na sociedade portuguesa. Visão histórica e perspectivas actuais. Actas do Colóquio. Coimbra, 20 a 22 de Março 1985. Coimbra: Instituto de História Económica e Social, Faculdade de Letras, 1986, p. 225.

${ }^{25}$ Cortes portuguesas. Reinado de D. Pedro I (1357-1367), op. cit., p. 60.

${ }^{26}$ Chancelarias Portuguesas. D. Pedro I (1357-1367), op. cit., p. 544-545, n. ${ }^{\circ} 1147$. 
Igualmente, em outros momentos, o monarca tem atitudes de amparo às minorias segregadas e que envolvem também uma atitude protetora do clero para com mouros e judeus.

O artigo $4 .^{\circ}$ das Cortes de Elvas, Capítulos do Clero, trata do fato de "que as nossas Justiças per ssy premdiam e mandauam tyrar per christãaos mouros judeus aquelles que se acolhiam as Igrejas em hos casos que o per direito canonico deuiam sseer defessos". Ao que o Rei responde "que a nos não prouue nem apraz (...) E mandamos que se nam ffaça daquy em diemte"27.

Nas mesmas Cortes, no artigo 9. ${ }^{\circ}$ dos Capítulos Especiais de Torres Novas, ao ser informado de que os judeus, por não possuírem um carniceiro em sua judiaria, recorriam aos açougueiros cristãos que não cumpriam o ritual judaico no abate, o que lhes levava a rejeitar a carne, o rei ordena aos juízes da vila e à todas as justiças do reino que "Renho por beem e mando que os ditos judeus aja carneçeiro Judeu E que lhes nom dem essas carnes per outra guisa, E mando aos juizes dessa villa e a todas as outras mhas Justiças que o façam assi compriir e aguardar... "28.

Também aos judeus de Beja ${ }^{29}$, Lisboa $^{30}$ e Santarém ${ }^{31}$ o mesmo monarca concede, em 1366, o privilégio de não serem obrigados a servir nas hostes da fronteira ou mesmo guardá-la, apesar de possuírem cavalos e armas por determinação real. O mesmo acontece para os mouros de Santarém ${ }^{32} \mathrm{e}$ Lisboa $^{33}$. Nestes últimos casos, proíbe ademais que se lhe obriguem a ter cavalos e armas se tivessem as contias que tornavam a posse obrigatória. Todavia, outras comunidades judaicas possuíam cavalos e armas, como em Beja $^{34}$ e Lisboa ${ }^{35}$.

A separação das comunidades foi uma necessidade em tempos de crise, mas, singularmente, o poder real passa a legislar em defesa dos novos espaços.

\footnotetext{
${ }^{27}$ Cortes portuguesas. Reinado de D. Pedro I (1357-1367), op. cit., p. 14-15.

${ }^{28}$ Ibidem, p. 127.

${ }^{29}$ Chancelarias Portuguesas. D. Pedro I (1357-1367), op. cit., p. 541-542, n. ${ }^{\circ} 1142$.

${ }^{30}$ Ibidem, p. 523, n. ${ }^{\circ} 1108$.

${ }^{31}$ Ibidem, p. 522-523, n. ${ }^{\circ} 1107$.

${ }^{32}$ Ibidem, p. 522, n. ${ }^{\circ} 1106$.

${ }^{33}$ Ibidem, p. 524, n. ${ }^{\circ} 1109$.

${ }^{34}$ Ibidem, p. 541-542, n. ${ }^{\circ} 1142$.

${ }^{35}$ Ibidem, p. 523, n. ${ }^{\circ} 1108$.
} 
Os judeus de Trancoso queixam-se ao rei de que, em sua judiaria, os cavaleiros e outras pessoas que chegavam à vila pediam pousada e eram mandados à judiaria para pousar e apossar-se de roupas e, se houvesse reclamações, eram agredidos. Também os corregedores, oficiais e escrivães ali iam pousar em ocasiões de feira e lhes tomavam o que ganhavam na feira. E a resposta real é surpreendente e nos inclina a pensar que o apartamento também pressupunha uma proteção real às minorias religiosas: "Tenho por bem e mando que nom seja nenhuum tam ousado de qualquer stado que seia tambem dos meus como dos Iffantes nem do conde como d'outros quaaesquer fidalgos nem corregedores nem seus officiaaes, nem scripvaães nem outros nenhuuns por poderosos que seiam que pousem na dita Judiaria nem que eles $d$ hi filhem roupa nem mandedes filhar que seia dos dictos judeus contra suas uontades (...) E a dicta comuna dos dictos Judeus tenham esta minha carta",36.

Para os mouros, acha-se o mesmo procedimento. Em 1362, favorece aos mouros de Évora ${ }^{37}$; aos de Elvas, em 1363, oferece privilégios que de maneira minuciosa, incluíam a proibição da tomada das galinhas, da palha e da cevada ${ }^{38}$, para além da roupa; e por fim beneficia aos mouros de Santarém, em $1364^{39}$.

Mas Pedro I vai além enfrentando proibições impostas por seu pai. Em 1357, agiliza o procedimento de compra de bens de raiz dos cristãos por parte dos judeus, evitando o aumento de custo a estes, que uma lei de Afonso IV necessariamente impunha ${ }^{40}$. Nas Cortes de Elvas, ao ser confrontado com uma suposta lei de seu pai, que impedia que os judeus levassem, aos seus devedores, outros bens que não as quantias devidas, responde no artigo $26 .^{\circ}$ dos capítulos gerais do povo “... que nos mostrem o mandado de nosso Padre e que nos lho faremos guardar como nos cabe e lhis faremos em elo mercee com aguizada Razom"41.

\footnotetext{
${ }^{36}$ Ibidem, p. 433-434, n. ${ }^{\circ} 937$.

${ }^{37}$ Ibidem, p. 297, n. $^{\circ} 638$.

${ }^{38}$ Ibidem, p. $364-365$, n. $^{\circ} 814$.

${ }^{39}$ Ibidem, p. 407, n. $^{\circ} 889$.

${ }^{40}$ Ibidem, p. 98-99, n. ${ }^{\text {o }} 289$.

${ }^{41}$ Cortes portuguesas. Reinado de D. Pedro I (1357-1367), op. cit., p. 44-45.
} 
Assim, é menos surpreendente nos depararmos com um pedido, aliás, bem justificado do ponto de vista da monarquia, no qual os cristãos requerem que lhes sejam retiradas as dívidas dos contratos feitos com os judeus "em tal tempo de mester que ssom constranjudos pera teerem cavalos e Armas pera nosso serviço e reccreçem lhes mesteres per mar e per terra pera nosso serviço e defendimento da terra e que outrossi ham de paguar soldadas e mantimentos", que recebe uma resposta categórica do rei: "A este Artigo Respondemos que ia esto per vezes foi dito a nosso Padre e a nos e he aguisado pagarem o que deuem poys que muitos tempos ouverom os christaaos pera pagar essas diuidas" ${ }^{42}$.

Assim, a ação de Pedro I não se presta a reducionismos. Se, por um lado, há uma clara tentativa de controle social, os limites que lhe são impostos dependem necessariamente da exigência de resguardar os privilégios e prerrogativas tradicionais, em especial em uma sociedade em que a tradição é a fiadora da legitimidade.

Por outro lado, como um cristão do século XIV, sua atitude para com os professantes de outros credos está firmemente imbricada em uma dialética que os aparta do convívio com o rebanho cristão, mas tenta evitar ao máximo os possíveis prejuízos e tensões sociais, em uma época de crise.

Seu sucessor, D. Fernando, acoimado por uma gama de problemas externos e internos, mantém todavia a mesma relação de seu pai e nos esclarece, ainda mais sobre o favor real à população judaica.

Às queixas nas Cortes de Lisboa de 1371, contra os privilégios concedidos aos judeus de serem nomeados almoxarifes e coletores de impostos do rei e de seus irmãos, por não dever existir deles "ssenhorio sobelos christaãos (...) o que era defeso per direito na santa escritura" ${ }^{43}$, responde o Rei que sua intenção era preservar os privilégios concedidos pelos seus antecessores. E isto acontece mesmo havendo uma lei de Afonso II que proibia qualquer autoridade de judeus sobre cristãos ${ }^{44}$.

${ }^{42}$ Ibidem, p. 48.

${ }^{43}$ Cortes portuguesas. Reinado de D. Fernando I (1367-1383). Edição preparada por MARQUES, A. H. de Oliveira e DIAS, Nuno José Pizarro Pinto. Volume I (1367-1380). Lisboa: Centro de Estudos Históricos da Universidade Nova de Lisboa - Instituto Nacional de Investigação Científica, 1990, p. 42.

${ }^{44}$ VELOSO, Maria Teresa Nobre, D. Afonso II: relações de Portugal com a Santa Sé durante o seu reinado. Coimbra: Arquivo da Universidade, 2000, p. 207 e 221. 
Também mostra que mesmo as medidas tomadas desde seu avô estavam longe de serem cumpridas e, ainda mais, eram burladas com o favor real, pois, tendo sido ordenado por D. Afonso IV que: "os Judeus trounesem signaaes nos peijtos pera sseerem conhoçudos" ${ }^{45}$, dizem os reclamantes que agora, o rei, "per (...) cartas" outorgava "a alguüs Judeus que os nom tragam"46.

E indo além, ainda que possamos entender como boatos maledicentes a queixa apresentada nas Cortes de 1372, em Leiria, de que o "nossos pouos são aggrauados uerem hora cousas nouas que non uirão nos tempos de nossos padres e de nossos auos e que auiaõ por estranho e que auiaõ por nosso serviço dizeren no llo que Judeus serem do nosso Conselhho e aueram nossas rendas auendo nossso senhoriomuitos bons que nos seruiriaõ lealmente " ${ }^{47}$, registamos que o rei D. Fernando responde ao clamor que "non auemos judeu que seia de nosso Conselho qua non o ouueriamos por nossa honra" auer por sem rezom auerem de ser rendeiros aquelles que por ellas mais derem qua esto faz cada hum e he em rezom de fazer em nos seus beins e cousas que tem" ${ }^{49}$. Ou seja, o rei nega a existência (verdadeira ou falsa) de judeus no Conselho Real, mas admite claramente as vantagens de ter judeus como rendeiros.

Tais leis demonstram as tentativas dos monarcas portugueses de obter um equilíbrio social. Tentativas frustradas, já o sabemos, pois cresciam no seio da sociedade tensões avassaladoras, cuja explicitação será trazida à luz no torvelinho de ódios e paixões marcados pela futura crise dinástica e pela Revolução de 1383.

No entanto, a tensão entre a proteção política e a repressão religiosa dos monarcas permanece e acabará por dar a vitória a esta última com a instauração, no final do século $\mathrm{XV}$, da perseguição ao criptojudaísmo inaugurada pela medida, no mínimo desastrada, de batizar a todos os judeus a serem expulsos em 1496, cristalizando um inimigo cotidiano a ser perseguido, em Portugal e nas colônias de além-mar.

\footnotetext{
${ }^{45}$ Cortes portuguesas. Reinado de D. Fernando I (1367-1383). I, op. cit., p. 55-56.

${ }^{46}$ Ibidem, p. 56.

${ }^{47}$ Ibidem, p. 134.

${ }^{48}$ Ibidem.

${ }^{49}$ Ibidem.
} 